\title{
PENGARUH GAME ONLINE TERHADAP CARA BELAJAR MAHASISWA JURUSAN PENDIDIKAN TEKNIK MESIN UNIVERSITAS NEGERI MANADO
}

\author{
Partonduhan Aritonang ${ }^{1}$, I. P. Tamba ${ }^{2}$, Jemmy Charles Kewas ${ }^{3}$ \\ 1,2,3 Jurusan Pendidikan Teknik Mesin, Universitas Negeri Manado, Kab. Minahasa \\ e-mail: partonduhan@gmail.com
}

\begin{abstract}
ABSTRAK
Mahasiswa Pendidikan Teknik Mesin Universitas Negeri Manado yang ialah murid murid perantau kini telah mendapatkan akibat yang sangat nyata dari game online ini. Terbukti dari banyaknya mahasiswa yang ada bagian dalam permainan ini, dari hasil pengamatan peneliti mahasiswa yang aktif mendapatkan data yang meluas bahwa mahasiswa Pendidikan Teknik Mesin Universitas Negeri Manado yang aktif bermain memiliki cara belajar yang kurang aktif dalam kegiatan belajar mengajar. Penelitian ini memakai metode penelitian deskriptif kuantitatif. Metode pengumpulan data memakai yakni kuisioner atau angket. Teknik analisi data yang digunakan dalam penelitian ini yaitu analisis statistik deskriptif, Teknik Analisis Regresi dan pengujian hipotesis. Hasil dari penelitian ini yakni : bahwa pengaruh game online $(\mathrm{X})$ terhadap cara belajar mahasiswa $(\mathrm{Y})$ pada taraf $t$ hitung $>t$ tabel dan hasil uji korelasi rxy 0849. Game online berpengaruh signifikan terhadap cara belajar. Ini dapat dibuktikan dari hasil nilai Fhitung sebesar 4.113 dan nilai signifikansi Ftabel $0.00<0.05$. Besarnya koefisien determinasi sebesar 0.79 atau 79\%. Hal ini berarti $79 \%$ pengaruh game online terhadap cara belajar mahasiswa sedangkan untuk selebihnya $21 \%$ dipengaruhi oleh variabel lain yang tidak diteliti oleh penelitian ini.
\end{abstract}

Kata kunci : Game Online, Cara Belajar Mahasiswa

\begin{abstract}
Manado university's advanced mechanical engineering student who is a migrant child has now had a very real impact on online gaming. It is evident from the many students participating in the game that researchers as active university students have received a wealth of data that students studying engineering at manado state university who actively play have a learning ability that is less active in learning. The study USES a quantitative descriptive study method. The data collection method used was "questionnaire or angket." The data analysis used in the study are descriptive statistical analysis, regression analysis and hypothetical testing. The results of this study are: that how online games affect students' learning (y) at a level of $t$ count $>t$ tables and rxy 0849 cordating results. Online games significantly affect how to learn. This can be verified from the results of the ftable value of 4,113 and the significance of ftable 0.00 . Critical coefficiencies by 0.79 or $79 \%$. This means $79 \%$ of the impact online games have on student learning while for the rest $21 \%$ are affected by other variables not examined by this study.
\end{abstract}

Key words : Game Online, student learning 


\section{PENDAHULUAN}

Game ini berkembang pesat dan membuat ketagihan. Selain sebagai cara berinteraksi dengan pengguna, game juga bisa menghilangkan penat dan kebosanan usai event. Fungsi dan grafik game yang semakin lama semakin baik, dan semakin nyata menjadi alasan mengapa banyak orang memainkannya, game ini dapat dimainkan secara online (multiplayer game). Perkembangan teknologi jaringan internet menjadi tempat yang menarik bagi para gamers untuk mengembangkan kreativitasnya di dunia online melalui game yang mereka minati (Syahputra, T. R. 2018). Peranan game online membuat pemainnya ketagihan sampai titik tersakit yaitu tidak mengingat masa sekolah, bekerja, dan lupa makan dan minum. Hampir semua game online akan memberikan dampak negatif terhadap sosial, psikologis dan fisik yang berujung pada kecanduan bermain game online. Secara sosial, hubungan dengan teman dan keluarga tidak dekat karena tidak ada waktu untuk berkumpul. Secara psikologis, otak terus menerus memikirkan permainan yang sedang dimainkannya (Amanda, R. A. 2016).

Cara belajar yang efektif merupakan cara belajar secara kuantitatif dan berkualitas, berkesinambungan sehingga menimbulkan perubahan secara akademis dan perilaku yang lebih baik. Belajar sering kali ditinggalkan oleh para siswa karena para siswa lebih mementingkan bermain. Oleh karena itu, siswa harus diberi motivasi agar mau belajar secara efektif di sekolah maupun dirumah. Dunia pendidikan saat ini sudah banyak, tidak seperti zaman dulu. Dulu mau sekolah susah karena faktor ekonomi keluarga, yang bisa sekolah hanya orang - orang tertentu saja. Akan tetapi sekarang hampir semua anak bisa sekolah dengan adanya bantuan dari pemerintah untuk anak yang kurang mampu yang ingin melanjutkan sekolah dan dengan program wajib 9 tahun dari pemerintah. Akan tetapi siswa sekarang masih banyak malas untuk belajar dan ada yang kesulitan dalam belajar. Dari masalah tersebut mengenai siswa yang malas untuk belajar dan siswa yang kesulitan dalam belajar di sekolah maupun di rumah adalah dengan memberikan pengetahuan tentang cara belajar yang efektif.
Cara belajar yang efektif ini digunakan agar siswa dapat belajar dengan baik dan mudah memahami pelajaran yang disampaikan disekolah. Tetapi siswa harus dimotivasi agar mau belajar secara efektif baik dirumah maupun di sekolah . karena, seorang siswa yang mempunyai cara belajar yang efektif memungkinkan untuk mencapai prestasi yang tinggi didalam pendidikan, sehingga bisa membuat bangga kedua orang tua.

Mahasiswa pendidikan teknik mesin di Universitas Negeri Manado, mereka adalah anak-anak dari desa terpencil, dan sekarang mendapatkan pengaruh paling nyata dari game online. Padahal, dari mahasiswa yang mengikuti game ini, dari sudut pandang penulis, data yang diperoleh mahasiswa aktif adalah mahasiswa pendidikan teknik mesin Universitas Negeri Manado yang aktif bermain game tidak belajar dalam belajar mengajar. Terlalu aktif.

Tempat bermain game online yang mudah dimainkan bagi mahasiswa pendidikan teknik mesin Universitas Negeri Manado. Dengan kemajuan zaman, game online dengan cepat membanjiri pelajar. Game online pertamanya masih tergantung situasi. Mengandalkan keefektifan sistem dan aturan yang sangat sederhana, permainan membekali siswa dengan wadah tunggal sebagai kegiatan yang sulit dilupakan.

Pembicaraan dalam metode belajar pertumbuhan technology disalahgunakan hendak dikenal mutu pembelajaran yang menyusut sebab buat bermain permainan online. Paradigm technology komunikasi media buat berikan Metode belajar baik dari aspek kognitif pada mahasiswa di masa modernisasi serta di masa era saat ini. Sesungguhnya perkembangan technology serta permainan online mewujudkan para pemain permainan online mewujudkan metode belajar yang merangsang mahasiswa malas, yang pada membuat tidak percaya dalam metode belajar mengajar. Setelah itu waktu pada belajar di pakai buat bermain permainan online. Mahasiswa jadi bangsa Indonesia di masa depan, pastinya wajib mengirim dirinya dari bermacam bidang. Salah satunya dari segi SDM yang mempunyai mutu yang bisa bersaing di masa era ini. Tetapi bisa di katakan ketinggalan, di tengah kemajuan technology yang sangat 
pesat, banyak mahasiswa yang tidak memakai technology itu dengan bijaksana, terlebih jika berdialog tentang permainan online. Spesialnya mahasiswa Jurusan Pembelajaran Metode Mesin.

Penanda variabel metode belajar ialah satu metode ataupun strategi gimana mahasiswa melakukan aktivitas belajar di antara lain (The Liang Gie, 1984) merupakan:

1) Mempersiapkan belajar, atmosfer orang yang buatnya siap buat memperoleh jawaban ataupun jawaban dalam metode tertentu terhadap kondisi

2) Menjajaki pelajaran, konsentrasi tenaga psikis tertuju kepada sesuatu objek serta sedikit bayaknya pemahaman yang menyertai suatu kegiatan yang dicoba.

3) Aktivitas belajar mandiri, aktivitas belajar aktif yang terbuat buat menanggulangi sesuatu permasalahan, serta dibangun dengan bekal pengetahuan yang dimiliki.

4) Pola belajar, sebagian rangkaian prosedur terhadap belajar yang bisa membantu mahasiswa dalam memahami modul kuliah. Dalam aktivitas belajar ini hendak merambat pada watak mahasiswa atas perilaku dosen serta aktivitas siswa dan ikatan sosial antara dosen serta murid.

5) Metode menjajaki tes, merasakan khasiat mengulang pelajaran dengan mempersiapkan seluruh suatu yang diperlukan.

Era zaman technology membuat peradaban terpenting pada kehidupan masyarakat memberikan ketidakpastian hubungan sosial ke dalam suatu dunia buatan. Ada sebagian dampak game online menurut pendapat (Yonandi, R., dan Nursalim, M. 2020) sebagai berikut:

a. Menjadi malas akan membuat kita lupa semuanya. Kita akan selalu serius pada game yang dimainkan. Kita akan tidak mengerjakan pekerjaan rumah atau mengerjakan tugas.

b. Kurang tidur sehingga menghabiskan sebagian besar waktunya pada belajar dikampus dan beraktivitas. Sehingga, banyak mahasiswa mengorbankan waktu berharga mereka menggunakannya untuk bermain game online. Penyakit candu game online yang tidak tidur akan dapat membahayakan tubuh dan pikirannya.

Kemudahan yang diberikan technology yang dimainkan kini merambat sangat candu. Mahasiswa maupun masyarakat saat ini sudah terkena candu pengaruhnya permainan ini seperti mahasiswa Pendidikan Teknik Mesin Universitas Negeri Manado. Pada awalnya mahasiswa ini tidak akan pernah lupa dari internet karena internet merupakan memang kebutuhan, hubungan di media sosial serta tuntutan pergaulan yang memungkinkan mahasiswa tidak dmudah untuk lepas dari internet. Tidak heran jika beberapa mahasiswa Pendidikan Teknik Mesin Universitas Negeri Manado terjebak di pada game online, akibatnya yang muncul terhadap cara belajar mahasiswa. Dari perkembangan zaman mengakibatkan cara belajar dipengaruhi technology dimana kegiatan belajar kurang aktif dalam kegiatan belajar mengajar. Salah satu cara dapat melihat dan mengetahui pendapat mahasiswa, maka dilakukan penelitian dengan cara memberikan pertanyaan ataupun pernyataan kepada mahasiswa dengan menyebarkan angket.

\section{METODE}

Penelitian tersebut ialah penelitian deskriptif kuantitatif. Deskriptif ialah dengan metode yang kegunaannya untuk menjelaskan atau memberi contoh pada objek yang diteliti melalui data atau sampel yang telah terkumpul kemudian tanpa melakukan analisis dan membuat kesimpulan yang berlaku untuk umum (Sugiyono. 2013). Penelitian kuantitatif adalah penelitian ilmiah yang sistematis terhadap bagian-bagian dan fenomena serta kausalitas hubunganhubungannya. Tujuan penelitian kuantitatif adalah mengembangkan dan menggunakan model-model matematis, teori-teori dan/atau hipotesis yang berkaitan dengan fenomena alam. Proses pengukuran adalah bagian yang sentral dalam penelitian kuantitatif karena hal ini memberikan hubungan yang fundamental antara pengamatan empiris dan ekspresi matematis dari hubungan-hubungan kuantitatif.

Penelitian kuantitatif banyak digunakan baik dalam ilmu alam maupun ilmu sosial, 
dari fisika dan biologi hingga sosiologi dan jur nalisme. Pendekatan ini juga digunakan sebagai cara untuk meneliti berbagai aspek dari pendidikan. Istilah penelitian kuantitatif sering dipergunakan dalam ilmu-ilmu sosial untuk membedakannya dengan penelitian kualitatif.

Teknik analisi data yang digunakan pada penelitian tersebut yaitu analisis statistik deskriptif, Teknik Analisis Regresi dan pengujian hipotesis. Teknik analisis deskriptif akan dilakukan dalam tida tahap yakni :

a. Editing, yaitu melihat lengkapnya dalam pengisian angket yang sudah dikumpulkan,

b. Skor, yaitu tahap selanjutnya yang memberi skor pada hasil responden yang menjawab diberi bobot nilai sebagai berikut:

Tabel 3. 4 Tabel Skoring

\begin{tabular}{|c|c|}
\hline Pertanyaan & Skor pernyataan \\
\hline sangat setuju & 4 \\
\hline Setuju & 3 \\
\hline Tidak setuju & 2 \\
\hline Sangat tidak setuju & 1 \\
\hline
\end{tabular}

c. Tabulating, pengelompokan data sesuai dengan tujuan penelitian kemudian dimasukkan kedalam tabel tabel yang telah ditentukan berdasarkan kuesioner yang telah ditentukan skornya presentasenya dengan menggunakan rumus distribusi frekuensi sebagai berikut:

$$
\mathrm{P}=\frac{F}{N} \mathrm{X} 100 \%
$$

Keterangan:

$\mathrm{P}=$ Prosentasee

$\mathrm{F}=$ Frekuuensi (jumlah jawaban responden)

$\mathrm{N}=$ Nuumber of cases

Teknik Analisis Regresi digunakan Untuk mengetahui seberapa kuat pengaruh variabel $\mathrm{X}$ (game online) terhadap variabel $\mathrm{Y}$ (cara belajar), Penelitian menggunakan rumus regresi linier sederhana sebaagai beriikut (Arikunto, 2013).

$$
\mathrm{Y}=\mathrm{a}+\mathrm{bx}
$$

Y: Nilai yang diprediksikan.

A: Konsstanta/ bila harrga $\mathrm{x}=0$.

b: Koefiisien reegresi.

$\mathrm{x}$ : Nilai variiabel Indeependen

Teknik Analiais Hipootesis dilaakukan dengan menggunakan uji Product moment uuntuk meliihat sejauh mana pengaruh (positif atau negatif) independent variable pada dependent variable. Pengujian hypotesis boleh dikatakan sebagai berikut:

jika signifikan $>0,05$ maka Ho diterima dan jika signifikan $<0,05$ maka Ho ditolak.

\section{HASIL DAN PEMBAHASAN}

\section{HASIL PENELITIAN BERMAIN GAME ONLINE}

Berikut ini hasil perhitungan persentase dari angket game online ada 10 pernyataan yang disebarkan kepada 61 mahasiswa Pendidikan Teknik Mesin Universitas Negeri Manado. Nilai mean modus dan range pada angket pengaruh game online dapat dijelaskan dibawah ini:

Tabel 4. 1 Hasil descriptive statistice

\begin{tabular}{|l|l|r|}
\hline \multicolumn{2}{|c|}{ Statistics } \\
\hline \multirow{2}{*}{ total_X } & Valid & 61 \\
\cline { 2 - 3 } & Missing & 0 \\
\hline Mean & 42.20 \\
\hline Median & 44.00 \\
\hline Mode & 47 \\
\hline Std. Deviation & 9.753 \\
\hline Range & 44 \\
\hline Minimum & 15 \\
\hline Maximum & 59 \\
\hline Percentiles & 25 & 35.50 \\
\cline { 2 - 3 } & 50 & 44.00 \\
\cline { 2 - 3 } & 75 & 48.50 \\
\hline
\end{tabular}

Untuk data variabel konsep diri diperoleh nilai maksimun (Max) 59, nilai minimum (Min) 15, Mean (M) 42.20, median (Me) 44, Modus (Mo) 47, dan Standar Deviasi (SD) 9.753 .

Jumlah kelas interval dapat dihitung menggunakan rumus Sturgees (Sugiyono 2010) sebagai berikut:

$\mathrm{K}=1+3,3 \log \mathrm{n}$

Keterangan:

$\mathrm{K} \quad=$ angka interval kelas 
$\mathrm{n} \quad=$ angka data

$\log \quad=$ logarithm

Jika jumlah data mahasiswa berjumlah 61 maka dapat dihitung jumlah interval kelasnya.

$$
\begin{aligned}
\mathrm{K} & =1+3.3 \log \mathrm{n} \\
& =1+3.3 \log 61 \\
& =1+5.89 \\
& =6.89 \text { dibulatkan jadi } 7
\end{aligned}
$$

Kelas interval yang berjumlah 7 , rentang kelas terbesar adalah $(59-15)=44$, setelah didapatkan rentang data jadi dicari panjang kelas yaitu 44/7 $=6.28$ dibulatkan 6 . Berikut tabel distribusi frekuensi dapat dilihat pada tabel pada tabel 4.2

Untuk memperjelas tabel maka dapat dibuat histogram batang sebagai berikut:

Dapat diketahui pada diagram batang diatas frekuensi terbesar adalah $42-47$ dengan frekuensi berjumlah 20 dan persentase $32.8 \%$. Untuk mengidentifikasi kecenderungan variabel game online dilakukan dengan

\begin{tabular}{|c|c|c|c|}
\hline \multicolumn{4}{|c|}{ Online } \\
\hline \multicolumn{4}{|c|}{ Game Online } \\
\hline No & Kategori & Frequency & Percent \\
\hline 1 & Sangat Rendah $(X \leq 27.95)$ & 4 & $6.6 \%$ \\
\hline 2 & Rendah $(27.95<\mathrm{X} \leq 34.65)$ & 10 & $16.4 \%$ \\
\hline 3 & Cukup $(34.65<\mathrm{X} \leq 40,65)$ & 5 & $8.2 \%$ \\
\hline 4 & Tinggi $(40.65<\mathrm{X} \leq 47.95)$ & 24 & $39.3 \%$ \\
\hline 5 & Sangat Tinggi $(X>47.95)$ & 18 & $29.5 \%$ \\
\hline & Total & 61 & $100 \%$ \\
\hline
\end{tabular}
pengkategorian menjadi 5 kategori dapat dilihat pada tabel dibawah ini.

Tabel 4. 3 Pengkategorian Variabel Game

Pada tabel menunjukkan bahwa frekuensi mahasiswa bermain Game Online pengelompokan ini sangat rendah berjumlah 4 mahasiswa (6.6\%), kategori rendah berjumlah 10 mahasiswa ( $16.4 \%$ ), kategori cukup berjumlah 5 mahasiswa (8.2\%), kategori tinggi berjumlah 24 responden (39.3\%), dan kategori sangat tinggi berjumlah 18 mahasiswa (29.5\%).

\section{HASIL PENELITIAN CARA BELAJAR}

Berikut ini hasil perhitungan persentase dari angket game online ada 10 pernyataan yang disebarkan kepada 61 mahasiswa Pendidikan Teknik Mesin Universitas Negeri Manado. Nilai mean modus range pada angket pengaruh game online dapat dijabarkan sebagai berikut:

Tabel 4. 4 Statistic Cara Belajar

\begin{tabular}{|l|l|r|}
\hline \multicolumn{3}{|c|}{ Statistics } \\
\hline Total_Y & Valid & 61 \\
\cline { 2 - 3 } & Missing & 0 \\
\hline Mean & 31.69 \\
\hline
\end{tabular}

\begin{tabular}{|l|r|}
\hline Median & 32.00 \\
\hline Mode & 35 \\
\hline Std. Deviation & 4.570 \\
\hline Range & 26 \\
\hline Minimum & 14 \\
\hline Maximum & 40 \\
\hline
\end{tabular}

Untuk data variabel cara belajar diperoleh nilai maksimun (Max) 40, nilai minimum (Min) 14, Mean (M) 31.69, Median (Me) 32, Modus (Mo) 35, dan Standar Deviasi (SD) 4.570 .

Jumlah kelas interval dapat dihitung menggunakan rumus Sturges (Sugiyono 2010)

\begin{tabular}{|c|c|c|}
\hline Interval & Frekuensi & Persentase \\
\hline $15-31$ & 9 & $14.7 \%$ \\
\hline $32-41$ & 14 & $22.9 \%$ \\
\hline $42-47$ & 20 & $32.8 \%$ \\
\hline $48-54$ & 14 & $22.9 \%$ \\
\hline $55-59$ & & $6.5 \%$ \\
\hline Jumlah & 61 & $100 \%$ \\
\hline
\end{tabular}

sebagai berikut:

Keterangan:

$$
K=1+3.3 \log n
$$

$\mathrm{K} \quad=$ jumlah interval kelass

$\mathrm{n} \quad=$ jumlah data

$\log \quad=$ logaritma

Jika jumlah data mahasiswa berjumlah 61 maka dapat dihitung jumlah interval kelasnya.

$$
\begin{aligned}
\mathrm{K} \quad & =1+3.3 \log \mathrm{n} \\
& =1+3.3 \log 61 \\
& =1+5.89 \\
& =6.89 \text { dibulatkan menjadi } 7
\end{aligned}
$$

Kelas interval yang berjumlah 7 , rentang kelas terbesar adalah (40-15) $=25$. Setelah didapatkan rentang data maka dapat dicari panjang kelas interval masing masing kelompok yaitu $25 / 7=3.57$ dibulatkan 4 . Berikut tabel distribusi frekuensi dapat dilihat pada tabel pada 
tabel

Cara Belajar

\begin{tabular}{|c|c|c|c|}
\hline \multicolumn{4}{|c|}{ Cara Belajar } \\
\hline No & Kategori & Frequency & Percent \\
\hline 1 & $\begin{array}{c}\text { Sangat Rendah }(\mathrm{X} \leq \\
21.45)\end{array}$ & 3 & $4.9 \%$ \\
\hline 2 & $\begin{array}{c}\text { Rendah }(21.45<\mathrm{X} \leq \\
25.15)\end{array}$ & 26 & $42.6 \%$ \\
\hline 3 & Cukup $(25.15<\mathrm{X} \leq 29,15)$ & 10 & $16.4 \%$ \\
\hline 4 & Tinggi $(29.15<\mathrm{X} \leq 33.45)$ & 1 & $1.6 \%$ \\
\hline 5 & $\begin{array}{c}\text { Sangat Tinggi (X } \\
>33.45)\end{array}$ & 21 & $34.4 \%$ \\
\hline \multicolumn{2}{|r|}{ Total } & 61 & $100 \%$ \\
\hline
\end{tabular}

Dapat diketahui pada diagram batang diatas frekuensi terbesar adalah 31 - 34 dengan frekuensi berjumlah 25 dan persentase $41 \%$. Untuk mengidentifikasi kecenderungan variabel game online dilakukan dengan pengkategorian menjadi 5 kategori dapat dilihat pada tabel dibawah ini.

Untuk memperjelas tabel maka dapat dibuat histogram batang sebagai berikut:

Tabel 4. 6 Pengkategorian Variabel Cara Belajar

\begin{tabular}{|c|c|c|}
\hline Interval & Frekuensi & Persentase \\
\hline $14-26$ & 5 & $8.1 \%$ \\
\hline $27-30$ & 12 & $19.7 \%$ \\
\hline $31-34$ & 25 & $41 \%$ \\
\hline $35-40$ & 19 & $31.2 \%$ \\
\hline Jumlah & 61 & $100 \%$ \\
\hline
\end{tabular}

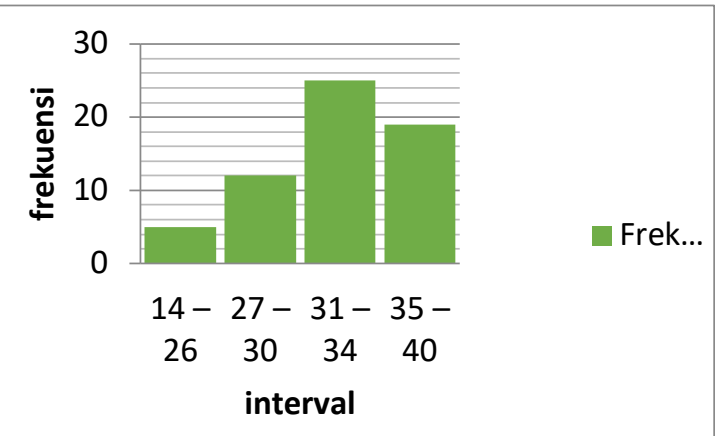

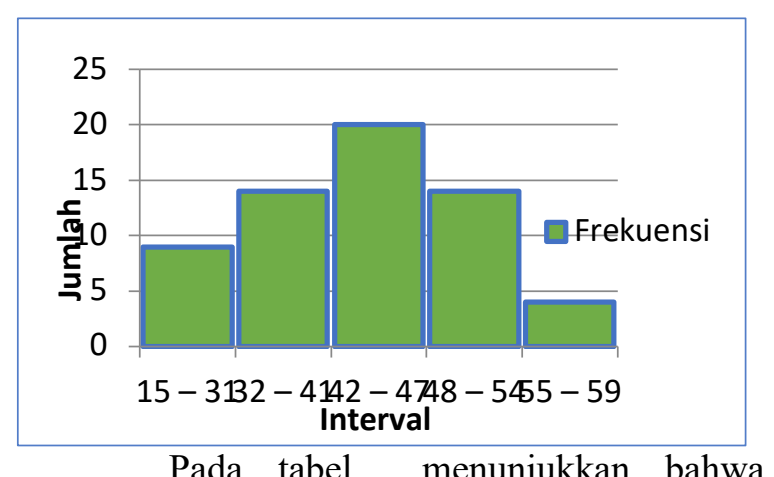

frekuensi mahasiswa bermain cara belajar pada kategori sangat rendah berjumlah 3 responden $(4.9 \%)$, kategori rendah berjumlah 1 responden ( $1.6 \%$ ), kategori cukup berjumlah 10 responden $(16.4 \%)$, kategori tinggi berjumlah 26 responden $(42.6 \%)$, dan kategori sangat tinggi berjumlah 21 responden $(34.4 \%)$.

Hasil analisis dari interprestasi data diambil kesimpulan bahwa terdapat pengaruh game online terhadap cara belajar mahasiswa. Hal ini dapat dilihat dari hasil perhitungan uji Anova yang menunjukkan bahwa nilai sig $0.849<0.05$, maka dari itu Ha diterima ada pengaruh game online terhadap cara belajar mahasiswa.

Hasil analisis regresi pada deskripsi uji simultan (Uji F) diperoleh dengan Fhitung sebesar 1.418 dengan nilai signifikansi Fhitung sebesar 1418 atau $F<0,05$. Dan Ftabel sebesar 2.461. Dari hasil penelitian menunjukkan bahwa terdapat pengaruh signifikan game online terhadap cara belajar mahasiswa.

Hasil analisis regresi sederhana menunjukkan bahwa koefisien determinasi (R2) sebesar 0.23 atau 23\%. Nilai koefisien determinasi dikatakan besarnya yang diberikan game online terhadap cara belajar. Hasil analisis tersebut menunjukkan bahwa pengaruh yang signifikan antara game online terhadap cara belajar mahasiswa Pendidikan Teknik Mesin Universitas Negeri Manado

\section{KESIMPULAN}

Dari hasil pengujian hipotesis dapat disimpulkan bahwa pengaruh game online (X) terhadap cara belajar mahasiswa (Y) pada taraf thitung ttabel dan hasil uji korelasi rxy 0849. Game online berpengaruh signifikan terhadap cara belajar. Ini dapat dibuktikan dari hasil nilai Fhitung sebesar 4.113 dan nilai signifikansi Ftabel $0.00<0.05$. Besarnya koefisien determinasi sebesar 0.79 atau $79 \%$. Hal ini 
berarti $79 \%$ pengaruh game online terhadap cara belajar mahasiswa sedangkan untuk selebihnya $21 \%$ dipengaruhi oleh variabel lain yang tidak diteliti oleh penelitian

online berpengaruh signifikan terhadap cara belajar. Ini dapat dibuktikan dari hasil nilai Fhitung sebesar 4.113 dan nilai signifikansi Ftabel $0.00<0.05$. Besarnya koefisien determinasi sebesar 0.79 atau $79 \%$. Hal ini berarti $79 \%$ pengaruh game online terhadap cara belajar mahasiswa sedangkan untuk selebihnya $21 \%$ dipengaruhi oleh variabel lain yang tidak diteliti oleh penelitian

\section{DAFTAR PUSTAKA}

.Sukmadinata, Nana Syaodih. (2012). Metode Penelitian Pendidikan
Syahputra, T. R. (2018). Pengaruh Bermain Game Online Terhadap Perilaku Komunikasi Remaja (Studi Pada Mahasiswa Pemain Game Online di Fakultas MIPA Jurusan Informatika Universitas Syiah Kuala Banda Aceh). Jurnal Ilmiah Mahasiswa Fakultas Ilmu Sosial \& Ilmu Politik, 3(1).

Sugiyono. 2013. Metode Penelitian Pendidikan Pendekatan Kuantitatif, Kualitatif, dan $R \& D$. Bandung: Alfabeta.

Sugiyono. 2007. Metode Penelitian Kuantitatif Kualitatif dan $R \& D$. Bandung: Alfabeta.

Sugiyono. 2010. Metode Penelitian Administratif. Bandung: Alfabeta 